\title{
Factors Affecting Treatment Outcome of Tuberculosis among Tuberculosis Patients in West Ethiopia
}

Jerusalem Israel Kassa ${ }^{1}$, Mohammed Gebre Dedefo ${ }^{2^{*}}$, Ayana Tadesse Korsa ${ }^{2}$ and Tesfa Tekle Dibessa ${ }^{2}$

${ }^{1}$ Dembi Dolo General Hospital, Oromia, Ethiopia

${ }^{2}$ Department of Pharmacy, Wollega University, Nekemte, Oromia, Ethiopia

\begin{abstract}
Background: Tuberculosis is a life threatening disease caused by mycobacterium tuberculosis. In developing countries the incidence of tuberculosis has been increasing steadily since the 1990s, particularly in African countries. Several European countries have lately reported a slight increase in tuberculosis, but these are mostly related to immigrants from high-incidence countries.

Objective: To assess the treatment outcomes of tuberculosis and its associated factors among tuberculosis patients on anti-tuberculosis therapy in Nekemte Referral Hospital, West Ethiopia.

Methods: A four years retrospective cross-sectional study was used and all patients' information that fulfilled the inclusion criteria was retrieved from records of patients with basic information for all registered patients. We analyzed the records of 315 tuberculosis patients who had known outcome in Nekemte Referral Hospital from September 2012-August 2016.

Results: From the total of 315 patients who had known treatment out come in Nekemte Referral Hospital, tuberculosis type was categorized as smear positive pulmonary TB in $68(21.5 \%)$, smear negative pulmonary TB in $107(34.0 \%)$, and extra pulmonary in $140(44.4 \%)$ cases. Records of the 315 TB patients showed that $54(17.01 \%)$ were cured, 206(65.4\%) completed treatment, 24(3.5\%) had treatment failure, 11(3.5\%) defaulted, 20(6.3\%) were died. The overall treatment success rate of the TB patients was $82.5 \%$. Age $\geq 45$ years $(A O R=7.1,95 \% \mathrm{Cl}=1.5-34.3$, $\mathrm{p}=0.014)$, smear negative PTB $(\mathrm{AOR}=3.4,95 \%, \mathrm{Cl}=1.5-9.5, \mathrm{P}=0.023)$ and retreatment cases $(\mathrm{AOR}=12.0,95 \%$, $\mathrm{Cl}=4.2-34.4, \mathrm{P}<0.001$ ) were significantly associated with unsuccessful treatment outcome.

Conclusion: Successful treatment outcome of TB patients was below standard. To improve treatment outcome among TB patients health education on the importance of TB treatment and the consequences of poorly treated TB have to be provided to patients during their follow up.
\end{abstract}

Keywords: Tuberculosis; Treatment outcome; Risk factors; Nekemte; Ethiopia

\section{Introduction}

Tuberculosis (TB) is a life threatening disease caused by mycobacterium tuberculosis: that are transmitted from person to person by coughing or sneezing, close contact of TB patients are most likely to become infected [1]. In 2016, there were an estimated 1.3 million TB deaths among HIV negative people (down from 1.7 million in 2000) and an additional 374000 deaths among HIV-positive people. An estimated 10.4 million people ( $90 \%$ adults; $65 \%$ male; $10 \%$ people living with HIV) fell ill with TB in 2016 (i.e. were incident cases) [2].

Most of the estimated number of incident cases in 2016 occurred in the WHO South-East Asia Region (45\%), the WHO African Region (25\%) and the WHO Western Pacific Region (17\%); smaller proportions of cases occurred in the WHO Eastern Mediterranean Region (7\%), the WHO European Region (3\%) and the WHO Region of the Americas (3\%). The top five countries, with $56 \%$ of estimated cases, were (in descending order) India, Indonesia, China, the Philippines and Pakistan [2].

In developing countries the incidence of TB has been increasing steadily since the 1990s, particularly in African countries. Several European countries have lately reported a slight increase in TB, but these are mostly related to immigrants from high-incidence countries [3].

According to the 2015 global, tuberculosis report tuberculosis (TB) is a major global health problem [4]. Over 95\% of new TB cases and deaths occur in low and middle income countries [5] the highest incidence of TB and the highest number of deaths due to TB occur in Asia and Saharan Africa [6]. The case fatality rate has exceeded $50 \%$ in some African countries where HIV infection rates are high [6-9].

The Stop TB Partnership has developed a Global Plan to End TB, 2016-2020, which focuses on the actions and funding needed to reach the 2020 milestones of the End TB Strategy. The End TB Strategy goal is to "End the global TB epidemic". The 2035 targets are a 95\% reduction in TB deaths and a $90 \%$ reduction in the TB incidence rate, compared with levels in 2015. The 2030 targets are a 90\% reduction in TB deaths and an $80 \%$ reduction in the TB incidence rate, compared with levels in 2015. The most immediate milestones, set for 2020 , are a $35 \%$ reduction in $\mathrm{TB}$ deaths and a $20 \%$ reduction in the $\mathrm{TB}$ incidence rate, compared with levels in 2015. The percentage of TB-affected households that experience catastrophic costs as a result of TB disease; the milestone for 2020 is zero, to be sustained thereafter [2]

*Corresponding author: Mohammed Gebre Dedefo, Department of Pharmacy Wollega University, Nekemte, Oromia, Ethiopia, Tel: +251 057-861-7981; E-mail: mohamedg@wollegauniversity.edu.et

Received January 19, 2018; Accepted February 15, 2018; Published February 22, 2018

Citation: Kassa JI, Dedefo MG, Korsa AT, Dibessa TT (2018) Factors Affecting Treatment Outcome of Tuberculosis among Tuberculosis Patients in West Ethiopia. J Bioanal Biomed 10: 24-29. doi:10.4172/1948-593X.1000200

Copyright: (c) 2018 Kassa Jl, et al. This is an open-access article distributed under the terms of the Creative Commons Attribution License, which permits unrestricted use, distribution, and reproduction in any medium, provided the original author and source are credited. 
The estimated decline in the incidence rate since 2010 has exceeded $4 \%$ per year in several high TB burden countries, including Zimbabwe (11\%), Lesotho (7\%), the United Republic of Tanzania (6.8\%), Ethiopia (6.7\%), Namibia (6.2\%), Kenya (5.0\%) and the Russian Federation $(4.2 \%)[10]$.

In 1993 the World Health Organization (WHO) announced a new strategy, called DOTS, for the worldwide control of TB. A DOT was the Directly Observed Treatment Short course strategy. All countries with a TB problem were to provide standardized short course drug treatment to, at least, all sputum smear positive TB patients [11]. In Ethiopia a standardized TB prevention and control programme, incorporating DOTS was started in 1992 [12].

The result of this study will serve as a representative quality of $\mathrm{TB}$ treatment provided by a health care system. It helps to improve treatment out come and adherence of the patients and it will also help to reduce treatment failure, drug resistance, relapse and death. Therefore this study will helps to assess treatment outcomes of pulmonary tuberculosis cases in Western Ethiopia.

\section{Methods}

\section{Study setting and period}

The study was conducted at Nekemte Referral Hospital, located $314 \mathrm{~km}$ to the west, away from capital city of Ethiopia, Addis Ababa. Nekemte Referral Hospital has different departments and wards like outpatient department (OPD), medical ward, gynecology and obstetrics ward, pediatrics ward and surgical ward. It delivers diversified health services and clinics including the emergency services, eye clinic, dental clinic, mother child health $(\mathrm{MCH})$, psychiatry clinic, laboratory, radiology, pharmacy, physiotherapy, follow up of chronic diseases, TB clinic and ART clinic. The study was conducted from September 2012-August 2016 at TB clinic.

\section{Study design}

A retrospective cross-sectional study was conducted.

\section{Study population}

All TB Patients undergoing treatments for TB in Nekemte Referral Hospital from September 2012-August 2016.

\section{Inclusion and exclusion criteria}

Patients registered for treatment of TB at Nekemte Referral Hospital from September 2012-August 2016 were included in this study and patients with incomplete data and patients who were transferred out from this hospital to other district hospital were excluded.

\section{Sample size determination and sampling technique}

All patients' information that fulfilled the inclusion criteria was retrieved from records of patients with basic information for all registered patients who took anti-tuberculosis treatment during the period of September 2012-August 2016.

\section{Data collection process}

The data was collected through medical record reviews of patients, by using a prepared check list. The data collectors were 2 BSc nurses who were briefed on how to proceed for data collection. Pre-test study was done before starting of the survey on 15 patients profile data; that was selected randomly to check the appropriateness and completeness of the check list.

\section{Data analysis and Interpretation}

Data was entered in to SPSS software version 20.0 social packages for analysis. Both bivariate and multivariate analyses were done by using binary logistic regression. Variables those having association in binary logistic regression was checked by multivariate logistic regression to identify confounders. A bivariate analysis was carried out to see the association between dependent and independent variables. All variables with $\mathrm{p}$ - value $<0.25$ was taken to multivariable model to control for all possible confounders Odds ratio along with $95 \%$ confidence level was estimated to identify factors associated with the outcome variable using multivariable logistic regression analysis. Level of statistical significance was declared at $\mathrm{p}$ - value $<0.05$ levels.

\section{Ethical considerations}

Ethical clearance was obtained from the Ethical Review Committee of Wollega University, College of Medical and Health Sciences. The patient data was accessed up on the approval of medical director of Nekemte referral hospital. Confidentiality was ensured during the data collection, thus the name of the patient were not recorded in the data collection check list.

\section{Definitions of terms}

Definition of treatment outcome according to the national TB and leprosy control program (NTLCP) guideline adopted from WHO [12]:

- Cured: - Finished treatment with negative bacteriology result at the end of treatment.

- Completed treatment: - Finished treatment, but without bacteriology result at the end of treatment.

- Failure: - remaining smear positive at five months despite correct intake of medication.

- Defaulted treatment: - Patients who interrupted their treatment for two consecutive months or more after registration.

- Died: - Patients who died from any cause during the course of treatment.

- Transferred out: - Patients whose treatment results are unknown due to transfer to another health facility.

- New case (N): A patient who never had treatment for TB or has been on previous anti-TB treatment for less than four weeks.

- Retreatment case(R) :- A patient declared cured or whose treatment was completed of any form of TB in the past but who reports back to the health service and in now found to be AFB smear positive or culture positive.

- Transfer in (T): A patient started treatment in one health institution and moved to another health institution to continue treatment.

- Successful treatment outcome: - if TB patient were cured or completed treatment with resolution of symptoms.

- Unsuccessful treatment outcome: - if treatment of TB patients resulted in treatment failure, default or death.

\section{Results}

\section{Socio demographic and clinical characteristics}

Total of 1807 tuberculosis patients were registered at Nekemte 
Referral Hospital from September 2012-August 2016. Out of these 1454 had been transferred out to other districts, 38 were on DOTs and 315 patients had known outcome at Nekemte Referral Hospital. Of these 163(51.7\%) were female and 152(48.3\%) were males. Most of the patients are within the age group of 15-29(46.3\%). Majority of the patients weight $(\mathrm{kg})$ were $40-59(71.1 \%)$ and $299(96.5 \%)$ were from urban (Table 1).

\section{Clinical characteristics of TB patients}

A total of 315 TB patients' data recorded from September 2012-August 2016 were analyzed. Among patients for whom disease category was documented, 68 (21.6\%) were smear-positive pulmonary TB, 107(34.0\%) had smear-negative pulmonary TB (PTB) and 140 (44.4\%) had extra pulmonary TB (EPTB). Out of the total TB patients enrolled in this study, cured 54(17.1\%), complete treatment 206(65.4\%), treatment failure 24(7.6\%), defaulted 11(3.5\%), and 20(6.3\%) were dead. Categories of patients were also documented for all types of TB patients: of these $264(83.8 \%)$ were classified as new cases, $25(7.9 \%)$ retreatment cases and $34(10.8 \%)$ transfer in. Majority of the patients 288(91.4\%) were on RHZE/RH (Table 2).

\section{Treatment outcome}

From the 315 patients evaluated for treatment outcome, 260 (82.5\%) had successful treatment outcome and 55(17.5\%) had unsuccessful treatment outcome. Of the patients with poor treatment outcome, 24 (7.6\%) had treatment failure, 11 (3.5\%) had defaulted and $20(6.3 \%)$ had died. There is no difference of treatment outcome between males and females. Patients with successful treatment outcome were younger than patients with poor treatment outcome and smear negative PTB patients had low treatment success rate when compared to smear positive PTB and extra pulmonary TB patients (Table 3 ).

\section{Determinants of TB treatment outcome}

The bivariable analysis showed that Age, TB type, treatment regimen and patients category were associated with low success rate. However, other factors like sex, residence, weight, HIV status, ART initiation, CPT initiation and year of treatment did not show significant association with poor treatment outcome (Table 4).

Variable with $\mathrm{P}$-value $<0.25$ (like age, weight, TB type, treatment regimen and patients category) were entered into multivariable

\begin{tabular}{|c|c|c|c|}
\hline Variables & Category & Frequency & Percentage \% \\
\hline \multirow{2}{*}{ Sex } & Female & 163 & 51.7 \\
\hline & Male & 152 & 48.3 \\
\hline \multirow{4}{*}{ Age } & $<15$ & 24 & 7.6 \\
\hline & $15-29$ & 146 & 46.3 \\
\hline & $30-44$ & 93 & 29.5 \\
\hline & $\geq 45$ & 52 & 16.5 \\
\hline \multirow{7}{*}{ Weight (kg) } & $<20$ & 12 & 3.8 \\
\hline & $20-29$ & 7 & 2.2 \\
\hline & $30-39$ & 20 & 6.3 \\
\hline & $40-49$ & 127 & 40.3 \\
\hline & $50-59$ & 97 & 30.8 \\
\hline & $60-69$ & 40 & 12.7 \\
\hline & $\geq 70$ & 12 & 3.8 \\
\hline \multirow{2}{*}{ Residence } & Urban & 299 & 94.9 \\
\hline & Rural & 16 & 5.1 \\
\hline
\end{tabular}

Table 1: Socio demographic characteristics of TB patients in Nekemte Referral Hospital, West Ethiopia, September 2012-August 2016. analysis. Factors that were significantly associated with poor treatment outcome at $\mathrm{p}<0.05$ in multivariable analysis were age, TB type, and patients category. While dealing with these factors, patients who are $\geq 45$ years are almost 7.1 times more likely to have poor treatment outcome than patients who are $<15$ years $(\mathrm{AOR}=7.1,95 \% \mathrm{CI}=1.5-34.3$, $\mathrm{p}=0.014$ ). Patients who had Smear negative PTB are 3.4 times more likely to have poor treatment outcome when compared with smear positive $\mathrm{PTB}$ patients (AOR $=3.4,95 \%, \mathrm{CI}=1.5-9.5, \mathrm{P}=0.023$ ). Patients with retreatment cases were 12 times more likely to have poor treatment outcome when compared with new cases $(\mathrm{AOR}=12.0,95 \%, \mathrm{CI}=4.2$ 34.4, $\mathrm{P}<0.001)$. However, other factors were not significantly associated with treatment outcome in Nekemte Referral Hospital (Table 4).

\section{Discussion}

In this cross-sectional study, the successful treatment outcomes of all TB types were $82.5 \%$ which is lower than the NTLCP and WHO target of $85 \%$. The finding of this study is consistent with the study conducted in Addis Ababa [13] which reported $82.7 \%$ of success rate. Our study showed that $17.1 \%$ and $65.4 \%$ of the TB patients attending DOTS were cured and completed treatment, respectively. These account an overall treatment success rate of $82.5 \%$. Different from this study other studies conducted in Northern Ethiopia had shown better treatment success rate $87.8 \%$ and $89.2 \%$ in Dabat [14] and Tigray [15] respectively. According to the report, the two main factors that contributed for the high success rate in the northern: health posts nearer to patients' residence and the use of volunteer community health workers (CHWs) or health extension workers (HEWs) in tracing patients who default from treatment to follow-up the patients are not yet done in Oromia region, Nekemte town. In addition, poor health system organization and deficient follow-up procedures could have contributed for poor treatment outcome. The patients' attitude and behavior towards the disease are also major factors influencing treatment adherence.

The finding of the present study showed that treatment success rate is better than other studies done in University of Gondar Teaching Hospital (60.1\%), Debremarkos (59.3\%), Gambella (55.7\%), Hadiya zones (38\%-73\%), and Northwest Ethiopia at Felege Hiwot Referral Hospital (26\%) [16-20]. The success rate in this study is also higher than studies done in Nigeria [21] and Malawi [22] which have reported success rate as $76.6 \%$ and $72 \%$ respectively. The comparably more successful treatment outcome recorded in this study shows the performance of institutional DOTS in TB control program in Nekemte Referral Hospital and improved awareness and adherence of TB patients to treatment that may signify the importance of the DOTS strategy.

In this study the unsuccessful treatment outcome of TB accounts for $17.5 \%$, which was comparable with study conducted in southern Ethiopia [23] that reported $16.7 \%$ unsuccessful treatment outcome. However the unsuccessful treatment outcome of this study is higher than studies from Southern Ethiopia at Dilla University Referral Hospital [24] and Tigray [15] which reported $14.8 \%$ and $10.8 \%$ of unsuccessful treatment outcome respectively. This could be due to difference in sample size and study settings. The treatment failure rate in this study comprised major portion of the unsuccessful outcome in TB treatment.

This study showed that smear negative PTB had significantly ( $p=0.023$ ) lower treatment success rate compared to the smear positive PTB and EPTB patients. Similarly studies from Tigray [15], Gondar [16] and southern region [23] showed that patients with smear negative PTB have poor treatment outcome. This could be due to high rate of 
Citation: Kassa JI, Dedefo MG, Korsa AT, Dibessa TT (2018) Factors Affecting Treatment Outcome of Tuberculosis among Tuberculosis Patients in West Ethiopia. J Bioanal Biomed 10: 24-29. doi:10.4172/1948-593X.1000200

\begin{tabular}{|c|c|c|c|}
\hline Variables & Category & Frequency & Percentage $\%$ \\
\hline \multirow{3}{*}{ Tuberculosis type } & Smear positive pulmonary TB & 68 & 21.6 \\
\hline & Smear negative pulmonary TB & 107 & 34.0 \\
\hline & Extra pulmonary TB & 140 & 44.4 \\
\hline \multirow{2}{*}{ Treatment regimen } & $\mathrm{RHZE} / \mathrm{RH}$ & 288 & 91.4 \\
\hline & RHZES/RHE & 27 & 8.6 \\
\hline \multirow{3}{*}{ HIV status } & Positive & 86 & 27.3 \\
\hline & Negative & 220 & 69.8 \\
\hline & not tested & 9 & 2.9 \\
\hline \multirow{2}{*}{ ART initiation for HIV positive patients } & Yes & 78 & 90.7 \\
\hline & No & 8 & 9.3 \\
\hline \multirow{2}{*}{ CPT information for HIV positive patients } & Yes & 80 & 93.0 \\
\hline & No & 6 & 7.0 \\
\hline \multirow{3}{*}{ Patient category } & New cases & 256 & 81.3 \\
\hline & Retreatment cases & 25 & 7.9 \\
\hline & Transfer in & 34 & 10.8 \\
\hline \multirow{3}{*}{ Smear result at 2 nd month for PTB +ve patients } & Positive & 0 & 0.0 \\
\hline & Negative & 60 & 19.0 \\
\hline & Not tested & 255 & 81.0 \\
\hline \multirow{3}{*}{ smear result at 5th month for PTB +ve patients } & Positive & 0 & 0.0 \\
\hline & Negative & 58 & 18.4 \\
\hline & not tested & 257 & 81.6 \\
\hline \multirow{3}{*}{ smear result at 7 th month for PTB +ve patients } & Positive & 0 & 0.0 \\
\hline & Negative & 53 & 16.8 \\
\hline & not tested & 262 & 83.2 \\
\hline \multirow{4}{*}{ Year of treatment } & September 2012-August 2013 & 106 & 33.7 \\
\hline & September 2013-August 2014 & 84 & 26.7 \\
\hline & September 2014-August 2015 & 90 & 28.6 \\
\hline & September 2015-August 2016 & 35 & 11.1 \\
\hline \multirow{5}{*}{ Treatment outcome } & Cure & 54 & 17.1 \\
\hline & Completed therapy & 206 & 65.4 \\
\hline & Failure & 24 & 7.6 \\
\hline & Default treatment & 11 & 3.5 \\
\hline & Dead & 20 & 6.3 \\
\hline
\end{tabular}

Table 2: Clinical characteristics of TB patients in Nekemte Referral Hospital, West Ethiopia, September 2012-August 2016.

\begin{tabular}{|c|c|c|c|c|c|c|c|}
\hline \multicolumn{2}{|c|}{ Characteristics } & \multirow{2}{*}{$\begin{array}{c}\text { Cure } \\
25\end{array}$} & \multirow{2}{*}{$\begin{array}{c}\text { Completed } \\
\text { therapy }\end{array}$} & \multirow{2}{*}{$\begin{array}{c}\text { Failure } \\
13\end{array}$} & \multirow{2}{*}{\begin{tabular}{|c|} 
Default treatment \\
5
\end{tabular}} & \multirow{2}{*}{$\begin{array}{c}\text { Died } \\
10\end{array}$} & \multirow{2}{*}{$\begin{array}{r}\text { Total } \\
163\end{array}$} \\
\hline Con & Female & & & & & & \\
\hline Sex & Male & 29 & 96 & 11 & 6 & 10 & 152 \\
\hline \multirow{4}{*}{ Age } & $<15$ & 1 & 21 & 1 & 0 & 1 & 24 \\
\hline & $15-29$ & 34 & 97 & 3 & 7 & 5 & 146 \\
\hline & $30-44$ & 16 & 63 & 2 & 4 & 8 & 93 \\
\hline & $\geq 45$ & 3 & 25 & 18 & 0 & 6 & 52 \\
\hline \multirow{2}{*}{ Residence } & Urban & 53 & 192 & 23 & 11 & 20 & 299 \\
\hline & Rural & 1 & 14 & 1 & 0 & 0 & 16 \\
\hline \multirow{3}{*}{ Tuberculosis type } & Smear positive PTB & 51 & 10 & 3 & 3 & 1 & 68 \\
\hline & Smear negative PTB & 1 & 77 & 12 & 7 & 10 & 107 \\
\hline & Extrapulmonary TB & 2 & 119 & 9 & 1 & 9 & 140 \\
\hline \multirow{3}{*}{ Patient category } & New cases & 44 & 178 & 12 & 7 & 15 & 256 \\
\hline & Retreatment cases & 5 & 6 & 8 & 4 & 2 & 25 \\
\hline & Transfer in & 5 & 22 & 4 & 0 & 3 & 34 \\
\hline \multirow{4}{*}{ Year of treatment } & Sept 2012-Aug 2013 & 21 & 67 & 5 & 5 & 8 & 106 \\
\hline & Sept 2013-Aug 2014 & 15 & 55 & 7 & 2 & 5 & 84 \\
\hline & Sept 2014-Aug 2015 & 13 & 60 & 8 & 3 & 6 & 90 \\
\hline & Sept 2015-Aug 2016 & 5 & 24 & 4 & 1 & 1 & 35 \\
\hline
\end{tabular}

Table 3: Treatment outcomes of TB patients by patient characteristics in Nekemte Referral Hospital, West Ethiopia, September $2012-$ August 2016. 
Citation: Kassa JI, Dedefo MG, Korsa AT, Dibessa TT (2018) Factors Affecting Treatment Outcome of Tuberculosis among Tuberculosis Patients in West Ethiopia. J Bioanal Biomed 10: 24-29. doi:10.4172/1948-593X.1000200

\begin{tabular}{|c|c|c|c|c|c|}
\hline \multirow{2}{*}{ Variables } & \multirow{2}{*}{ Categories } & \multicolumn{2}{|c|}{ Treatment outcome of TB } & \multirow{2}{*}{ COR $(95 \% \mathrm{Cl}) \quad \mathrm{P}$ value } & \multirow{2}{*}{ AOR $(95 \% \mathrm{CI}) \mathrm{P}$ value } \\
\hline & & Successful & Unsuccessful & & \\
\hline \multirow{3}{*}{ Age } & $<15$ & 22 & 2 & 1 & 1 \\
\hline & \multirow{2}{*}{$\begin{array}{c}15-29 \\
30-44 \\
\geq 45\end{array}$} & $\begin{array}{c}131 \\
79\end{array}$ & $\begin{array}{l}15 \\
14\end{array}$ & $\begin{array}{l}\text { 1.3(0.3-5.9) } P=0.769 \\
1.9(0.4-9.2) P=0.400\end{array}$ & $\begin{array}{l}0.9(0.2-4.3) P=0.872 \\
1.4(0.3-6.7) P=0.705\end{array}$ \\
\hline & & 28 & 24 & $9.4(2.0-44.3) \mathrm{P}=0.004$ & $7.1(1.5-34.3) \mathrm{P}=0.014$ \\
\hline \multirow{7}{*}{ Weight } & $<20$ & 11 & 1 & 1 & \\
\hline & $20-29$ & 7 & 0 & $0.0(0.0) P=0.999$ & -- \\
\hline & $30-39$ & 13 & 7 & $5.9(0.6-55.9) P=0.120$ & -- \\
\hline & $40-49$ & 101 & 26 & $2.8(0.4-22.9) \mathrm{P}=0.329$ & -- \\
\hline & $50-59$ & 85 & 12 & $1.6(0.2-13.1) \mathrm{P}=0.686$ & -- \\
\hline & $60-69$ & 33 & 7 & $2.3(0.3-21.1) \mathrm{P}=0.451$ & -- \\
\hline & $\geq 70$ & 10 & 2 & $2.2(0.2-28.1) P=0.544$ & -- \\
\hline \multirow{3}{*}{ Tuberculosis type } & Smear positive PTB & 61 & 7 & 1 & 1 \\
\hline & Smear negative PTB & 78 & 29 & 3.2(1.3-7.9) $P=0.010$ & 3.4(1.2-9.5) $P=0.023$ \\
\hline & Extrapulmonary TB & 121 & 19 & 1.4(0.5-3.4) $P=0.504$ & $2.0(0.7-6.1) P=0.202$ \\
\hline \multirow{2}{*}{ Treatment regimen } & $\mathrm{RHZE} / \mathrm{RH}$ & 242 & 46 & 1 & -- \\
\hline & RHZES/RHE & 18 & 9 & $2.6(1.1-6.2) P=0.028$ & -- \\
\hline \multirow{3}{*}{ Patient category } & New cases & 222 & 34 & 1 & 1 \\
\hline & Retreatment cases & 11 & 14 & 8.3(3.5-19.8) $P<0.001$ & $12.0(4.2-34.4) \mathrm{P}<0.001$ \\
\hline & Transfer in & 27 & 7 & $1.7(0.7-4.2) P=0.255$ & $1.7(0.6-4.5) \mathrm{P}=0.316$ \\
\hline
\end{tabular}

Table 4: Logistic regression analyses of factors associated with treatment outcome in TB patients at Nekemte Referral Hospital, West Ethiopia, September 2012-August 2016.

HIV co-infection in this group of patients, which may decrease the treatment success and increase mortality.

This study also showed that the patients with age of $\geq 45$ years had significantly $(\mathrm{p}=0.014)$ low TB treatment outcome. This finding is similar to other studies done in Tigray [15] and southern region [23]. This might be associated with increased co-infections with other diseases as well as the general physiological deterioration with age that might contribute to poorer treatment outcome [25,26].

Retreatment cases also showed that significant association $(\mathrm{P}<0.001)$ with poor treatment outcome. The poor treatment outcome of TB patients obtained in this study was similar with a study done in Tigray [15], Gondar [16] and southern region [23]. High proportion of poor outcome in retreatment cases in this study might occur due to sub-optimal therapy and drug resistance.

This study did not show differences in treatment outcome for gender and residence, however a study done in southern region [23] showed that being male is associated with poor treatment outcome, this might be due to males are highly exposed to cigarette smoking alcohol consumption, which might contribute to poor treatment outcomes and a study done in Dilla university referral hospital [24] showed that being from rural area was associated with poor treatment outcome this might be due to low DOTS performance, inadequate health seeking behavior and lower patient awareness about TB treatment. The reason for the differences could be due to difference in sample size and study settings.

Limitations of this study was that being retrospective made us not to study important variables including education level, distance from the treatment center, patient-health worker communication, delay in health care seeking and provider and health system related factors which could affect TB treatment outcome. Tuberculosis patients transferred to other health facilities were also not included.

\section{Conclusion}

Successful treatment outcome of TB patients in Nekemte Referral Hospital during our study was $82.5 \%$. The unsuccessful treatment outcome was significantly associated with age, type of TB and patients category thus, patients with older age, smear negative pulmonary $\mathrm{TB}$ and patients with retreatment cases requires attention to improve treatment outcome. To improve treatment outcome of TB, emphasis has to be given by the health care professionals, regional health bureau and ministry of health in providing health education on the importance of TB treatment and the consequences of poorly treated TB.

\section{Acknowledgment}

We are thankful to Wollega University for their unreserved cooperation in making this study to be a fruitful work. We are also thankful for data collectors

\section{Competing Interests}

No competing interests between authors.

\section{Reference}

1. Dipiro JT, Talbert RL, Yee Gc, Matzke GR, Wells BG, et al. (2014) Pharmacotherapy, A Pathophysiologic Approach. (9 ${ }^{\text {th }}$ edn), McGraw-Hill Education.

2. World Health Organization (2017) Global tuberculosis report 2017. Geneva Switzerland.

3. World Health Organisation (2005) WHO report 2005. Global tuberculosis control: Surveillance, planning and financing. Geneva, Switzerland.

4. World health organization (2015) Global TB control: WHO report 2015. World health organization, Geneva, Switzerland.

5. UNFPA: United Nations fund population activities. (2013) Tuberclosis a global health emergency 17: 179 .

6. World health organization (2011) Global tuberculosis control: WHO report 2011. WHO, Geneva, Switzerland.

7. De Cock K MSB, Cooulibaly IM, lucas SB (1992) Tuberculosis and HIV infection in sub-saharan Africa. JAMA 268: 1581-1587.

8. World health organization (2010) Global tuberculosis control: WHO report 2010. WHO, Geneva, Switzerland.

9. WHO Tuberculosis (TB) Data (2009) Global tuberculosis control: a short up date to the 2009 report. Geneva.

10. World health organization (2016) Global tuberculosis control: WHO report 2016. WHO, Geneva, Switzerland.

11. World Health Organization (1999) What is DOTS? A Guide to understanding 
Citation: Kassa JI, Dedefo MG, Korsa AT, Dibessa TT (2018) Factors Affecting Treatment Outcome of Tuberculosis among Tuberculosis Patients in West Ethiopia. J Bioanal Biomed 10: 24-29. doi:10.4172/1948-593X.1000200

the WHO-recommended TB control strategy known as DOTS. World Health Organization, Geneva, Switzerland.

12. Federal Ministry of Health Ethiopia (2008) tuberculosis, leprosy and TB/HIV prevention and control programme. ( $4^{\text {th }}$ edn) Manual, Addis Ababa: $\mathrm{MOH}$.

13. Getahun B, Ameni G, Medhin G, Biadgilign S (2013) Treatment outcome of tuberculosis patients under directly observed treatment in Addis Ababa, Ethiopia. Braz J Infect Dis 17: 521-528.

14. Tadesse S, Tadesse $T$ (2014) Treatment success rate of tuberculosis patients in Dabat, northwest Ethiopia. Health 6: 306-310.

15. Berhe G, Enquselassie F, Aseffa A (2012) Treatment outcome of smearpositive pulmonary tuberculosis patients in Tigray Region, Northern Ethiopia. BMC Public Health 12: 537

16. Tessema B, Muche A, Bekele A, Reissig D, Emmrich F, et al. (2009) Treatment outcome of Tuberculosis patients at Gondar University Teaching Hospital, Northwest Ethiopia. A five-year retrospective study. BMC Public Health 9: 371.

17. Esmael A, Tsegaye G, Wubie M, Abera H, Endris M (2014) Treatment outcomes of tuberculosis patients in Debremarkos referral hospital, North West Ethiopia: a five year retrospective study. IJPSR 5: 1500-1505.

18. Sisay S, Mengistu B, Erku W, Woldeyohannes D (2014) Directly Observed Treatment Short-course (DOTS) for tuberculosis control program in Gambella Regional State, Ethiopia: ten years' experience. BMC Res Notes 7: 44.

19. Shargie EB, Lindtjørn B (2005) DOTS improves treatment outcomes and service coverage for Tuberculosis in South Ethiopia: a retrospective trend analysis. BMC Public Health 5: 62.
20. Biadglegne F, Anagaw B, Debebe T, Anagaw B, Tesfaye W, et al. (2013) A retrospective study on the outcomes of tuberculosis treatment in Felege Hiwot Referral Hospital, Northwest Ethiopia. Int J Med Med Sci 5: 85-91.

21. Fatiregun AA, Ojo AS, Bamgboye AE (2009) Treatment outcomes among pulmonary tuberculosis patients at treatment centers in Ibadan, Nigeria. Ann Afr Med 8: 100-104.

22. Harries AD, Nyirenda TE, Banerjee A, Boeree MJ, Salaniponi FM (1999) Treatment outcome of patients with smear-negative and smear-positive pulmonary tuberculosis in the National Tuberculosis Control Programme Malawi. Trans R Soc Trop Med Hyg 93: 443-446.

23. Muñoz-Sellart M, Cuevas LE, Tumato M, Merid Y, Yassin MA (2010) Factors associated with poor tuberculosis treatment outcome in the Southern Region of Ethiopia. Int J Tuberc Lung Dis 14: 973-979.

24. Gebrezgabiher G, Romha G, Ejeta E, Asebe G, Zemene E, et al. (2016) Treatment Outcome of Tuberculosis Patients under Directly Observed Treatment Short Course and Factors Affecting Outcome in Southern Ethiopia: A Five-Year Retrospective Study. PLoS ONE 11: e0150560.

25. Cayla JA, Caminero JA, Rey R, Lara N, Valles X, et al. (2004) Working Group on Completion of Tuberculosis Treatment in Spain: Current status of treatment completion and fatality among tuberculosis patients in Spain. Int J Tuberc Lung Dis 8: 458-464.

26. Falzon D, Le Strat Y, Belghiti F, Infuso A. Euro TB Correspondents (2005) Exploring the determinants of treatment success for tuberculosis cases in Europe. Int J Tuberc Lung Dis 9: 1224-1229. 